\title{
The Effectiveness of a 3D-Virtual Reality Learning Environment (3D-VRLE) on the Omani Eighth Grade Students' Achievement and Motivation towards Physics Learning
}

\author{
https://doi.org/10.3991/ijet.v15i05.11890
}

Asma Al-Amri

Ministry of Education, Muscat, Oman

Mohamed Osman, Ali Al Musawi (四)

Sultan Qaboos University, Muscat, Oman

asmusawiesqu.edu.om

\begin{abstract}
This study aimed to examine the effectiveness of a 3D-Virtual Reality Learning Environment the Omani 8th-grade students' achievement and motivation towards physics learning. To achieve the study objectives, data were collected using two instruments: an achievement test and a motivation questionnaire. The sample consisted of sixty-five female students. They were divided into two groups, (32) students in the experimental group and (33) students in the control group. The findings of this research study indicated a greater improvement in students' achievement in physics after using the 3D-VRLE compared to their counterparts in the traditional learning environment. Furthermore, the results showed that the 3D-VRLE has a positive effect on students' motivation towards physics learning. In the light of these findings, the study recommended the importance of using the 3D-VRLE in the Ministry of Education schools. Research areas for future investigation in the field of the 3D-VRLEs were also suggested.
\end{abstract}

Keywords - 3D-virtual reality learning environment; academic achievement, motivation, science education, physics.

\section{Introduction}

The Trends in the International Mathematics and Science Study (TIMSS) shows that science teachers face many issues [1]. Some studies and reports [2] [3] indicate that the students at various levels have difficulties in understanding many science concepts causing a weakness in the level of school achievement in this subject. Moreover, it has been noted that science teachers face various challenges in terms of appropriate methods to teach and explain abstract concepts and make science lessons more attractive to the students. In particular, teaching physics comes with both risks and complexity of concepts' understanding [2]. However, experiments that are carried 
out at a school laboratory are usually limited due to safety issues or limited time and space [4]. Nowadays, there is an increased focus on Science, Technology, Engineering and Mathematics (STEM) teaching through which educators are responsible to find the appropriate curriculum, methods, and resources to meet the new expectations and prepare their learners as future scientists [5].

Researchers notice that using teaching aids and technologies in education can have positive effects on teaching and learning [6] \& [2]. [7] points out that the current technological revolution has contributed to the improvement of students' achievements level and motivated them to be more engaged. [8] emphasize that "...technology is taking the education to innovative ways, much more attractive to the students, making possible the use of new tools, taking to an evolution on the teaching process." (p. 295). As technology has helped to develop the educational tools in a unique way, the teachers constantly keep searching for technologies which make learning more effective, enjoyable and enable students learning [9].

Science topics, in particular, are mostly affected by technology due to the nature of the laboratories work, equipment, and media [10]. The use of Information Technology (IT) in science teaching enables students to conduct laboratory experiments and activities to study the scientific phenomena [2]. In particular, the 3D-Virtual Reality Learning Environment (3D-VRLE) can be implemented to help achieving the instructional objectives in the classroom [11] [12] [13].

\section{Conceptual Framework of Study}

The 3D-VRLE takes a significant role in new science teaching methods. Many studies show the effectiveness of 3D-VRLE in the completing laboratory experiments and improving the students' understanding of abstract ideas [2]. The learning environment created by this virtual lab allows students to interact with objects that they may not be able to do in normal situations [11]. Additionally, the 3D-VRLE has been widely used as an educational tool because of its feasibility and cost effectiveness [14]. There are many studies linking the 3D-VRLE with improvements in students' academic performance and motivation towards learning [14] [8] [2]. [5] indicates that the 3D-VRLE is effective in increasing academic achievement, enhancing engagement, and developing the 21 st century competencies like collaboration, communication, and technology use. It can provide students with more motivation and attention to the learning process as it enables them to explore and construct their own science knowledge and make learning more interesting and fun [8].

It is then possible to use this type of learning environments in the Omani context in order to raise the level of students' achievement and enhance their motivation towards the learning process. For example, [2], prepared in cooperation with the Ministry of Education, indicates that the Oman national and international assessments of learning show that students' performance is below the government's expectations and many other countries in the world. The Report also shows that Omani students perform poorly in math, English and science subjects. In response to this shortcoming, the Report summary call for educational reforms that "...emphasize change in teaching, 
learning and assessment methodologies, update the curriculum, add additional resources, improve facilities, reduce class sizes and upgrade the qualifications and skills of teachers" (p.6). Using the 3D-VRLE could become one type of these resources that may have a considerable effect on learning activities, change the teaching process and enhance students' learning [11]. Research evidence that the 3D-VRLE can be an effective tool for science teaching in the Omani context is asserted by the studies of [10] and [15]. More investigations are yet required to provide field evidence specifically in teaching science subjects such as physics where this technology may not have been previously used for systematic use in the Omani context.

Based on [3], Omani schools suffer from poor achievement of students in various subjects, most important of which is science. The reasons behind this include several factors such as the lack of facilities, lab resources and/or innovative presentation methods. There are also some educational situations where it is not possible to use direct experiences due to safety issues, scarcity and/or cost. In such a case, there may be a need to use the virtual learning environments as an alternative system to improve students' level and their motivation towards the learning process.

In summary, the literature shows a consensus among researchers regarding the worthiness and importance of using 3D-VRLE technology in teaching and learning [14] [8] [2] [16]. This study was conducted to investigate the effect of using 3DVRLE technology on Omani students' performance in physics. It aims to examine the effectiveness of using 3D-VRLE in the Omani schools in students' achievement and motivation towards physics learning.

\section{Study Objectives and Hypotheses}

The study attempts to achieve the following objectives:

- Examine the effects of a 3D-VRLE on 8th grade students' academic achievement in physics

- Investigate the effects of a 3D-VRLE on 8th grade students' perceived motivation toward physics learning

The following null hypotheses were formulated and tested at $5 \%$ level of significance:

- Null hypothesis 1 of No significant difference between the two groups

- Null hypothesis 2 of No significant differences between the two groups

\section{$4 \quad$ Methodology}

The quasi-experimental method research design was applied in this study to investigate the effect of 3D-Virtual Reality Learning Environment (3D-VRLE) on the Omani 8th grade students' achievement and their motivation towards science learning. A pre-posttest control group design was used to compare between two experi- 
mental and control groups. The control group learned in a traditional learning environment using books, board or PowerPoint presentations, whereas the experimental group taught using the 3D-VRLE.

\subsection{Instruments}

The study used the following instruments for data collection:

The achievement test: To measure the impact of using the $3 \mathrm{~d}$-virtual learning environment on the students' achievement, the test was designed and constructed in accordance with the Ministry of Education (MOE) tests' specifications. Both the preand posttest was similar in the content, but the order of the questions was different to avoid the set response effect. The test consisted of (30) questions and aimed to assess the students' achievement in the topics of waves, light and sound in physics. The maximum score for the test was 30 marks. For each question, participants received a score of either 1 (correct answer) or 0 (incorrect answer), with a total score ranging from 0 to 30. The questions distributed in the following ratios: 50\% (15 questions) of Application Questions, 30\% (9 questions) of Knowledge Questions and 20\% Questions (6 questions) of Inference.

Validity and reliability of the test: A review panel of 10 subject matter experts assessed the content validity of the achievement test. After modifications, the reliability of the test was measured by applying it on another basic school from the same educational region with (31) 8th grade female students. As a result, the last version of the pre- and posttest contained (30) items with Cronbach's alpha coefficient of 0.72 .

Motivation questionnaire: Students' perceived motivation toward physics learning in 3D-VRLE has been measured using Keller ARCS inventory which stands for the four components of ARCS model: Attention, Relevance, Confidence, and Satisfaction. The original instrument has (36) items with an alpha coefficient of 0.95 [17]. A translated version of the inventory was reviewed and tested for both validity and reliability. The reliability coefficient was found to be 0.90 .

\subsection{Sample}

The participants of this study were all 8th grade students in Al-Dakhlia region's schools in Oman. Based on the simple random sampling technique, the sample encompassed one school (Um Ayman Basic Education in Izki City) and consisted of 65 students of the 8th grade. They were all female students and aged from 13-14 years. They were divided into the two groups comprised (32) students in the experimental group and (33) students in the control group.

\subsection{Procedures}

The classroom environment was designed to make the learning process interesting and motivating. The educational content was presented in an engaging pedagogical style and in appropriate small doses that were easy for the students to absorb. These educational experiences which followed by interactive evaluation questions and tests 
enabled the teacher to ensure that students were engaged and to follow up their development. They were interacting with the evaluation questions and recorded their results and answers where the teacher was able to follow through their educational achievement during or after the class. The experiment in this study went through the following steps:

- Researcher distributed students randomly in two groups. The aim of a random

- Distribution was to get a statistical equivalence among the two groups.

- Before beginning the experiment, a training workshop conducted for the teachers and

- Students prior to the empirical part to train them to use the lessons in the 3DVRLE.

- Researcher observed the teaching process of both the experimental and the control

- Groups.

- A pre-test was given to both groups to assure the equivalency between the two groups in the achievement and motivation level.

- After the treatment, an achievement test was administrated to compare the results between the two groups and a motivation questionnaire was administrated for the experimental group to measure the students' motivation toward learning physics.

\section{Description of Learning Environment and Materials}

The 3D-Virtual Environment: Eureka ${ }^{\circledR}$ product as a 3D-VRLE along with the other teaching materials to conduct the experiment. The environment is a digital instructional package, called "Eureka.in Top-Bottom 3D Content", which has a large collection of digital units, animated movies, and simulations, in different physics subject (Figure 1). The product was developed be Designmate Company. It was selected because of its suitability to explain and demonstrate the physics topics and concepts in an interactive way. It was used in teaching the (Unit 4: Waves and its Applications) in grade 8th science curriculum and used for 8 weeks comprising 16 lessons with 2 classes per a week.
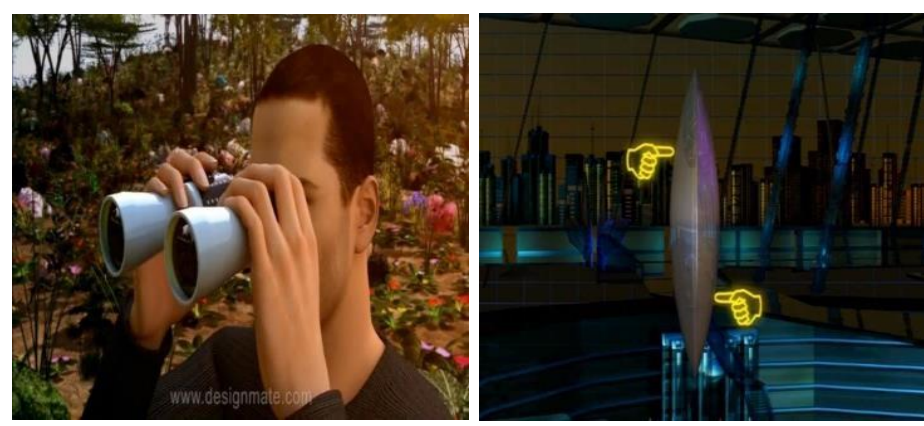

Fig. 1. 3D- Video Explains the Convex Lenses Topic by Eureka (https://www.designmate.com/) 
Additionally, the lab has simulations feature that allows students to manipulate different variables, predict, and visualize the results (Figure 2). These simulations were available for some of the digital lessons. They served as a mini virtual laboratory when students manipulated the variables in the given reactions and predicted the results.

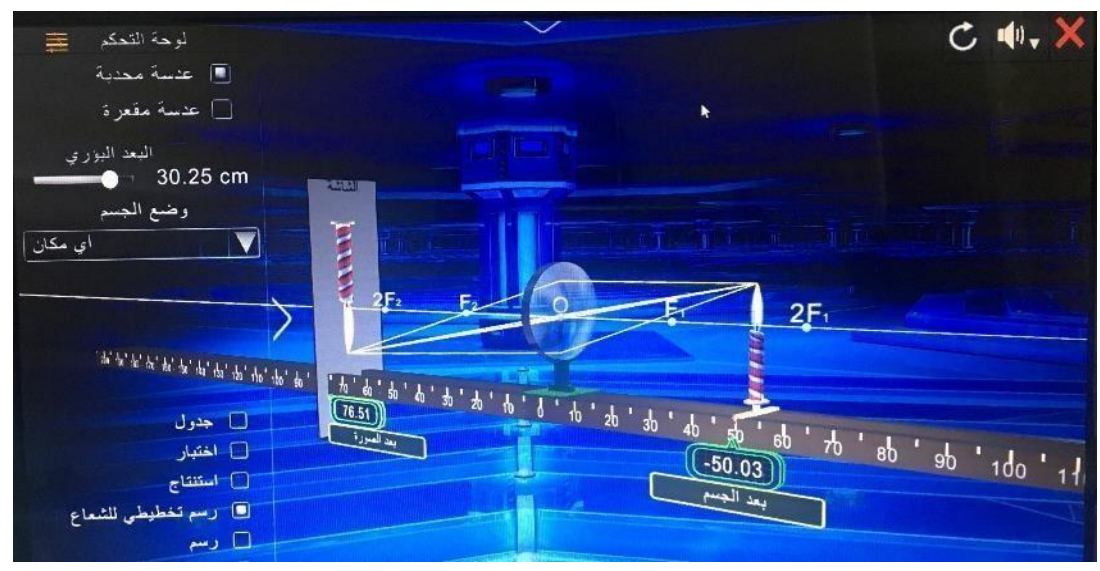

Fig. 2. 3D- Simulation in the Light Topic by Eureka (https://www.designmate.com/)

Web Based Educational Resources. Additional teaching resources and learning objects were used in order to assist and support student learning besides the "Eureka.in Top-Bottom 3D Content" product. These Web- based educational resources were used as supportive tools during the classes. Internet provided rich opportunities for the teacher to employ many different entry points to learning. One of these websites was $\mathrm{PhET}$ (https://phet.colorado.edu/ar_SA/simulations/category/physics) which is an Interactive simulations project initiated by the University of Colorado Boulder to create free interactive math and science simulations. All simulations were extensively tested and evaluated to ensure their educational effectiveness. The simulations were written in Java, Flash or HTML5 and can be run online or downloaded to the students' computers. In this study, a number of relevant 3D-simulations from PhET was downloaded to the students' computers, and integrated in the topics of (sounds, waves and lights). The students were engaged in these simulations through an intuitive game-like environment where students learn through exploration and discovery (Figure 3).

The other educational website that was used as an assistive teaching source was the skoool website (http://www.skoool.com.eg/Default.aspx?tabid=87). It has many interactive flash lessons used to support the interaction between teachers and students in the classroom (Figure 4). In addition, the 3D-virtual classroom itself offered a combination of different resources, which are 3D-videos, 3D- simulations, interactive quizzes, and display web links to instructional video clips, learning objects, and interactive text-based documents. 

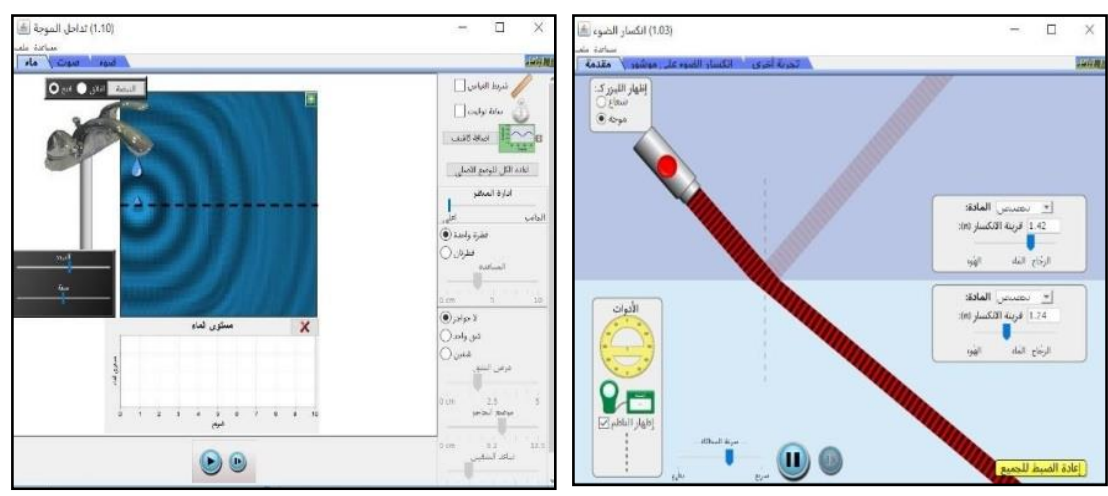

Fig. 3. Dynamic Simulation of Interfere of Wave Refraction of Light by Phet (https://phet.colorado.edu/ar_SA/simulations/category/physics)
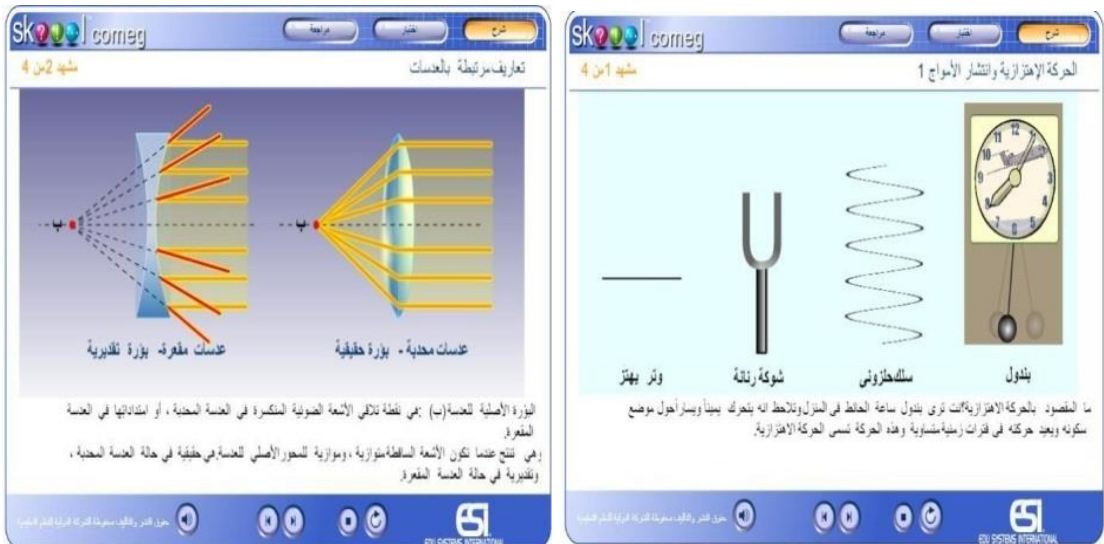

Fig. 4. 3D Interactive Lessons in Skoool Website by Skooolhttp://www.skoool.com.eg/Default.aspx?tabid=87)

All these resources were used as scaffolds for the student learning process to encourage them to engage with knowledge in active and dynamic ways. The use of multimedia and the flexibility in using the teaching resources enabled the teacher to meet the learning styles of all students.

\section{$6 \quad$ Results}

In order to test the study's hypotheses, two main types of statistical analysis were conducted:

- Independent sample t-test was conducted to compare the means of the control and experimental groups on the posttest 
- Paired sample t-test was conducted to compare students' motivation toward physics learning in the experimental grou

The following section explains the research findings:

\subsection{Research hypothesis 1}

In reference to the effect of a 3D-VRLE on students' academic achievement, an independent sample T-Test was conducted to compare the mean scores on students' achievement on the posttest between the experimental and control groups. Table 1 below summarizes the descriptive and inferential analysis of the data.

Table 1. Independent Sample t-test of the Mean Posttest Scores

\begin{tabular}{|l|c|c|c|c|c|c|}
\hline \multicolumn{1}{|c|}{ Groups } & $\mathbf{N}$ & $\mathbf{d} \boldsymbol{f}$ & Mean & Std. Deviation & t- value & Sign. (2- tailed) \\
\cline { 1 - 2 } Control & 33 & \multirow{2}{*}{63} & 17.48 & 4.45 & \multirow{2}{*}{6.22} & \multirow{2}{*}{0.001} \\
\cline { 1 - 2 } & 32 & & 23.88 & 3.80 & & \\
\hline
\end{tabular}

$*$ Total score $=30$

The results in table 1 reveal a significant difference between the two groups in the students' achievement. For instance, it is noticed through the table that (t-value = $6.22, p=0.001, \alpha=0.05$ level) in favor of the experimental group with a mean score of 23.88 for the experimental group, and 17.48 for the control group. This shows that students of the experimental group which uses the 3D-VRLE significantly performed better than their counterparts in the control group with a large effect size of (Cohen's d $=.38$ ). Consequently, the null hypothesis of No significant difference between the two groups can be rejected. Thus, there is a considerable change in students' achievement and understanding of the concepts of the waves and its applications unit.

These results appear to be in agreement with previous researchers who have asserted on positive impact on students' academic achievement after using 3D-VRLE in science teaching [18] [19] [20] [21] [16] [22] [23] [24] are similar to the current study in their context of the study, kind of the virtual reality environment used, the research design, and the research instruments used.

However, the results of this research are not in congruence with some previous researches (e.g. [25], [26]. This is perhaps due to the type of the virtual laboratories and environments used and the different contextual factors.

\subsection{Research hypothesis 2}

In order to test the effect of the 3D-VRLE on students' motivation toward physics learning, a paired sample t-test was conducted to compare the level of students' motivation of the experimental group before and after the treatment. Table 2 shows the statistics of the paired- sample t-test of pre and post-motivation questionnaire responses of the experimental group. 
Paper-The Effectiveness of a 3D-Virtual Reality Learning Environment (3D-VRLE) - Virtual Reality...

Table 2. Paired- Sample t-test of Pre and Post-Motivation Questionnaire Responses

\begin{tabular}{|l|c|c|c|c|c|c|}
\hline \multicolumn{1}{|c|}{ Test } & N & df & Mean & Std. Deviation & t- value & Sig.(2- tailed) \\
\hline Pre-Motivation Test & 32 & \multirow{2}{*}{31} & 98.91 & 17.76 & \multirow{2}{*}{12.85} & \multirow{2}{*}{.001} \\
\cline { 1 - 2 } & 32 & & 152.13 & 12.51 & & \\
\hline
\end{tabular}

*Maximum score $=180$

Table 2 reveals a significant difference between the mean scores on the motivation questionnaire responses of students before and after the experiment $(\mathrm{t}=12.85, \mathrm{p}=$ $.001, \alpha=.05$ ), with mean scores of 98.91 for the pre-motivation test and 152.13 for the post- motivation test. The findings indicated that the use of 3D-VRLE in physics learning accounts for $84.2 \%$ of the variance in the students' motivation toward physics learning $(\eta 2=0,842)$. Thus, the null hypothesis of No significant differences is rejected.

These findings were also found in congruence with similar studies [22] and [16]). However, these findings were in disagreement with the [19] study which showed no differences between the two groups in terms of motivation toward learning after using this environment. Nevertheless, this may be due to the difference in context and sample of the study.

\section{$7 \quad$ Conclusion and Implications}

This study was conducted to investigate the effectiveness of 3D-virtual reality learning environment (3D-VRLE) on the Omani eighth-grade students' achievement and motivation towards physics learning. The findings indicated that 3D-VRLE can contribute to enhancing both students' academic achievement in physics and at the same time raises the interest and motivation toward learning physics. As one of the first studies of its kind, it asserted that there is an importance of using the 3D-VRLE in the learning process and it has great potential in the education field and can be used in different subjects. The results were consistent with the literature of most of the previous studies.

The pre- and posttest revealed that students who were exposed to the 3-VRLE in the learning process show a greater improvement on students' achievement in physics compared to the other group who have been taught in a traditional way. In addition, the analyses of independent t-test which showed that 3D-VRLE affected positively the students' academic performance. In brief, there is a relationship between applying this kind of learning environments and the academic achievement of the students.

Based on Keller ARCS motivation inventory, the findings show that the 3D-VRLE has a positive effect on student learning motivation. The used 3D-VRLE is attentive, relevant, satisfied the students' needs and increases their confidence during the learning process and that leads to the enhancement of learners' engagement and motivation. Although the used desktop-based 3-D virtual environments in the current study did not provide a fully immersive experience, their photo realistic computer graphics have shown to enhance learners' engagement and motivation. According to the previ- 
ous research, researchers find that VRLE improves students learning motivation significantly.

Accordingly, the following recommendations can be suggested:

- Practical recommendations: If MOE plans to apply this technology in the Omani schools, it has to pay attention to the provision of all that will make the 3D-VRLE success in schools such facilities, support, training and curricular development. Human resources that can assist in this provision should be made available especially instructional developers and programmers. Partnership with other counterparts and corporates is required

- Currently, studies are not sufficient to display the effect of 3D-VRLE in the learning process on the Omani educational context. Therefore, the researcher offers some suggestions for future studies, including a similar study can be conducted for different curricula other than physic, such as math, biology or chemistry and for different sample. In addition, other research can be done in the area of studying the effectiveness of the use of 3D-VRLE in the development of critical thinking skills in other courses in different stages of the study. In addition, a study to examine the current capabilities of the Ministry of Education (MOE) and its readiness to apply 3D-VRLE in Omani schools can also be conducted

\section{$8 \quad$ References}

[1] Anderman, E. Sinatra, G. (2012). The Challenges of Teaching and Learning about Science in the 21st Century: Exploring the Abilities and Constraints of Adolescent Learners. Studies in Science Education Journal, 48(1), 89-117. https://doi.org/10.1080/03057267.2012.65 $\underline{5038}$

[2] Shudayfat, E. (2014). Teaching and learning in 3D Multiuser Virtual Environments. (Doctoral dissertation), University Politehnica of Bucharest. Retrieved from: http://graphics.cs. pub.ro/theses/phd/2014/eman.shudayfat/Teza\%20Eman\%20Shudayfat.pdf

[3] The World Bank (2012). The drive for quality. The Ministry of education, Oman. Retrieved from: http://documents.worldbank.org/curated/en/280091468098656732/pdf/7571 90ESW0v20W0ector0Report0English.pdf

[4] Georgiou, J. Dimitropoulos, K. Manitsaris, A. (2007). A Virtual Reality Laboratory for Distance Education in Chemistry. International Scholarly and Scientific Research \& Innovation 1(11), 617-624. Retrieved from: https://publications.waset.org/14203/pdf

[5] Smith, T. (2014). Elementary Science Instruction: Examining a Virtual Environment for Evidence of Learning, Engagement, and 21st Century Competencies. Education Sciences - Open Access Journal, (1), 122-138. Retrieved from: https://files.eric.ed.gov/fulltext/ EJ1117875.pdf

[6] Reeves, T. (1998). The Impact of Media and Technology in Schools (A Research Report prepared for the Bertelsmann Foundation). Retrieved from: http://birbhum.nic.in/DPSC/ref erence/69.pdf

[7] Costley, K. (2014). The Positive Effects of Technology on Teaching and Student Learning. Online Submission, ERIC, https://files.eric.ed.gov/fulltext/ED554557.pdf

[8] Piovesan, S. Passerino, L. Pereira, A. (2012, Oct.). Virtual Reality as a Tool in the Education. Paper presented at the International Association for Development of the Information 
(IADIS) International Conference on Cognition and Exploratory Learning in Digital Age (CELDA), Madrid, Spain. Retrieved from: https://eric.ed.gov/?id=ED542830

[9] Brown, J. (2011). Does the Use of Technology in the Classroom Increase Students Overall Academic Performance? (Masters dissertation), Gonzaga University. http://web02.gon zaga.edu/comltheses/proquestftp/Brown_gonzaga_0736M_10115.pdf

[10] Al-Musawi, A. Ambusaidi, A. Al-Balushi, S. Al-Balushi, K. (2015). Effectiveness of ELab Use in Science Teaching at The Omani Schools. The Turkish Online Journal of Educational Technology, 14(1), 45-52.

[11] Shudayfat, E. Moldoveanu, F. and Moldoveanu, B. (2012). A 3D Virtual Learning Environment for Science teaching in High School. Proceedings of the 23rd International DAAAM Symposium, Volume 23, No. 1 (pp. 423-428). Retrieved from: http://www.daaam.info/Downloads/Pdfs/proceedings/proceedings_2012/0423_Shudayfatat al.pdf

[12] Wu, J. (2018). A Space Design Teaching Model Using Virtual Simulation Technology, iJET 13(6), 138-159. https://doi.org/10.3991/ijet.v13i06.8585

[13] Wang, F. (2019). Computer Distance Virtual Experiment Teaching Application Based on Virtual Reality Technology, iJET 13(4), 138-159. https://doi.org/10.3991/ijet.v13i04.8472

[14] Lee, E.A-L., Wong, K.W. and_Fung, C.C. (2009) Learning effectiveness in a desktop virtual reality-based learning environment. In: Kong, S.C., et al (Eds.), Proceedings of the 17th International Conference on Computers in Education [CDROM]. Hong Kong: AsiaPacific Society for Computers in Education (pp. 832-839). Retrieved from: https://core.ac. uk/download/pdf/11237833.pdf

[15] Al-Balushi, S. M., Al-Musawi, A. S., Ambusaidi, A. K., \& Al-Hajri, F. H. (2016). The effectiveness of interacting with scientific animations in chemistry using mobile devices on grade 12 students' spatial ability and scientific reasoning skills. Journal of Science Education and Technology, 26(1), 70-81. https://doi.org/10.1007/s10956-016-9652-2

[16] Ma, B. \& Mak, P. (2000). Using Virtual Reality in Teaching Secondary School Physics, Online Submission, Retrieved from: https://pdfs.semanticscholar.org/b86f/219b24517a 745f7fb1e20b77496aab90161e.pdf? ga $=2.65140590 .1993685676 .1569656644-$ 1896641391.1566664480

[17] Keller, J. M. (2006). Development of two measures of learner motivation: CIS and IMMS. Online Manuscript, Retrieved from: https://studylib.net/doc/7446614/developmentof-two-measures-of-learner-motivation

[18] Chen, C. H., Yang, J. C., Shen, S., \& Jeng, M. C. (2007). A Desktop Virtual Reality Earth Motion System in Astronomy Education. Educational Technology \& Society, 10 (3), 289304. https://pdfs.semanticscholar.org/b61e/79140bf96ae5f4f351d78b0318243ae71cc2.pdf

[19] Alsultanny, Y. Nouby, A. Al-Enazi, T. (2014). Effects of using Simulation in E-learning Programs on Misconceptions and Motivations towards Learning. International Journal of Science and Technology Education Research, 5(2):40-51. https://doi.org/10.5897/IJSTER2 $\underline{010.043}$.

[20] Tüysüz, C. (2010). The Effect of the Virtual Laboratory on Students' Achievement and Attitude in Chemistry. International Online Journal of Educational Sciences, 2(1), 37-53, Retrieved from: http://citeseerx.ist.psu.edu/viewdoc/download?doi=10.1.1.657.6059\&rep=re p1\&type=pdf

[21] Faour, M.A. \& Ayoubi, Z. (2018). The effect of using virtual laboratory on grade 10 students' conceptual understanding and their attitudes towards physics. Journal of Education in Science, Environment and Health (JESEH), 4(1), 54-68. Retrieved from: https://doi.org/ $\underline{10.21891 / \text { jeseh.387482 }}$ 
[22] Ahmad, A. (2010). The effect of using a virtual lab on the physics concepts achievement acquisition of higher-order thinking skills and motivation toward science learning among students of the third preparatory class. Scientific Journal of Education, 13(6), 1-46, Egypt. (In Arabic)

[23] Zhang, M., Zhang, Z., Chang, Y., Aziz, E., Esche, S., Chassapis, C. (2018). Recent Developments in Game-Based Virtual Reality Educational Laboratories Using the Microsoft Kinect, iJET 13(1), 138-159. https://doi.org/10.3991/ijet.v13i01.7773

[24] Zacharia, Z. C. (2007). Comparing and combining real and virtual experimentation: an effort to enhance students' conceptual understanding of electric circuits. Journal of Computer Assisted Learning, 23(2), 120-132. https://doi.org/10.1111/j.1365-2729.2006.00215.x

[25] Alqurashi, S. F. (2013). The Effect of Using Virtual Labs in Teaching a Unit of Science Course on the Academic Achievement of First Grade Intermediate Students in Makkah City. (Masters dissertation), Umm Al-Qura University, Mecca, Saudi Arabia.

[26] Merchant, Z. (2012). The Impact of Virtual Reality-based Learning Environment Design Features on Students' Academic Achievements (Doctoral dissertation), Texas A \& M University. Retrieved from: https://oaktrust.library.tamu.edu/bitstream/handle/1969.1/148077/ Merchant\%2c\%20Zahira.pdf?sequence $=1 \&$ isAllowed $=\mathrm{y}$

\section{Authors}

Asmaa Yousuf Al Amri (a.alaameri86@gmail.com) is a curriculum designer at the IT Curriculum Department of the Ministry of Education. She has obtained her M.Ed. in educational technology in 2019 from the Instructional and Learning Technologies Department at the College of Education of Sultan Qaboos University. She has presented papers and workshops at many conferences and workshops.

Mohamed Eltahir Osman (mosman@squ.edu.om) is an Associate Professor of Instructional Systems Technology. He is currently the HOD of Instructional \& Learning Technologies Department, College of Education at Sultan Qaboos University. He also served as the Assistant Dean for Post Graduate Studies \& Research, He has presented and researched extensively on issues related to web-based learning environments, student empowerment, technology integration in teaching and learning, and systemic improvement of school performance. He has also served on editorial boards, and as a reviewer for a number of journals including the American journal of Educational Technology Research \& Development. More information can be found on his personal web page at: www.mtosman.com/en

Ali Sharaf Al Musawi is a professor at the Instructional and Learning Technologies Department at the College of Education of Sultan Qaboos University. He has obtained his PhD on learning resources and technology centers in 1995 from Southampton University, UK. He works for the Sultan Qaboos University since 1985. At present, He has published numerous journal research articles, chapters in reviewed books, and papers; and contributed in many conferences, symposia, and workshops. He conducted and published several national, regional, and Arab studies and reports. He wrote a book on cooperative learning in 1992, contributed in writing another in 2003 and an educational lexicon in 2014; and published a book on learning resources and technology centers in 2004. He also translated, with others, two books on elearning strategies and instructional multimedia to Arabic in 2005 and 2010. Prof. Ali 
Paper - The Effectiveness of a 3D-Virtual Reality Learning Environment (3D-VRLE) - Virtual Reality...

has several activities in the fields of instructional skills development, study skills, instructional design, and web-based design; his interests include Arabic poetry; he published two anthologies in addition to other hand-written ones.

Article submitted 2019-10-17. Resubmitted 2019-11-21. Final acceptance 2019-11-23. Final version published as submitted by the authors. 